\title{
Torsional Resistance of Two New Heat Treated Nickel Titanium Rotary Instruments: An in Vitro Evaluation
}

\author{
Gianluca Gambarini ${ }^{1}\left[\right.$, Gabriele Miccoli ${ }^{\circledR}$, Dario Di Nardo ${ }^{\circledR}$, Andrea Del Giudice ${ }^{1}$, Alessandro

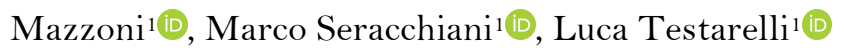

'Department of Oral and Maxillo-facial Sciences, “Sapienza” University of Rome, Rome, Italy.

Author to whom correspondence should be addressed: Dario Di Nardo, Via Caserta 6, o0161, Rome, RM, Italy. Phone: +39 3343795174. E-mail: dario.dinardo@,uniroma1.it.

Academic Editor: Yuri Wanderley Cavalcanti

Received: 13 March 2020 / Accepted: 08 June 2020 / Published: 11 August 2020 How to cite this article: Gambarini G, Miccoli G, Di Nardo D, Del Giudice A, Mazzoni A, Seracchiani M. Torsional
resistance of two new heat treated nickel titanium rotary instruments: an in vitro evaluation. Pesqui Bras Odontopediatria
Clín Integr. 2020; 20:e0053. https://doi.org/10.1590/pboci.2020.156

\begin{abstract}
Objective: To evaluate the difference in torsional resistance, angular deflection and fragment length between two new rotary instruments: AF Blue S4 and S-One. These files share all features except crosssectional design. Material and Methods: A total of 40 new Nickel-Titanium instruments of $25 \mathrm{~mm}$ in length were tested in this study and divided in two groups: 20 AF Blue S4, tip 25 and constant $6 \%$ taper and $20 \mathrm{AF}-\mathrm{Blue} \mathrm{S} 4$ tip 25 and constant $6 \%$ taper. The torsional test was performed by the use of a torque recording endodontic motor (KaVo, Biberac, Germany). Torque to Fracture (TtF), Angular Deflection (AD) and Fragment Length (FL) was recorded for each instrument. To ensure an immovable block at $3 \mathrm{~mm}$ of the instrument tip, an auto-polymerizing resin (DuraLay; Reliance Dental Mfg Co, Worth, IL) was used. Each file was rotated clockwise at a speed of 300 rpm until fracture occurred. Results: Group A (AF Blue S4) showed higher $\mathrm{TtF}$ and $\mathrm{AD}$ than Group $\mathrm{B}$ (S-One), and statistical analysis found significant differences between the two instruments $(\mathrm{p}<0.05)$. The mean values for FL showed no significant differences $(\mathrm{p}>0.05)$ between the two instruments. Conclusion: The AF Blue $\mathrm{S} 4$ seems to have a higher resistance to torsional stress in vitro. Clinically, the use of AF Blue S4 could be safer in narrow canals.

Keywords: Endodontics; Dental Alloys; Torsion, Mechanical; Torque.
\end{abstract}




\section{Introduction}

The introduction of nickel-titanium (NiTi) rotary instruments in endodontics improved the quality of root canal treatments (RCTs), in terms of shaping and cleaning of root canals [1]. Despite the superior qualities of the nickel-titanium alloy compared to the traditional Stainless-Steel instruments, the risk of unexpected intracanal separation could still occur [2,3]. The fracture of nickel-titanium rotary instruments during root canal treatment represents a major drawback for clinicians, affecting the treatment prognosis. Therefore, it is imperative to understand file's fracture mechanisms [4]. Flexural and torsional stresses occurring during intracanal rotation, both by themselves and combined, are the two causes of rotary files fracture [5].

The cyclic fatigue failure results from continual tension and compression stress on the maximum root canal curvature area. This pattern of fracture on NiTi rotary instruments was investigated in many studies in the literature [6-10]. Thanks to these studies, the factors influencing cyclic fatigue resistance are well known; therefore, it is possible to predict the cyclic fatigue resistance of an instrument just knowing its metallurgical characteristics.

The separation due to torsional stress occurs when the tip or part of the instrument binds into the canal, and the remaining part of the instrument continues to rotate and the torsional resistance of the instrument is overloaded [11]. Nevertheless, doubtful information is available on torsional resistance. Two main factors affect torsional resistance, such as metal mass and heat treatment. While the literature agrees on the influence of heat treatment, more studies are necessary to understand the role of metal mass on torsional resistance [12,13]. Some articles state that the main influence of mass on torsional resistance is related to the total amount of mass, while other studies emphasize the importance of mass distribution along the instrument $[14,15]$.

At present, the method of choice for testing static rotational resistance is evaluating instruments as described by the International Organization for Standardization (ISO) 3630-1 [16]. According to this test, in order to generate a continuous torsional load, a $3 \mathrm{~mm}$ file tip was fixed while the file is rotated with the speed of $2 \mathrm{rpm}$. This method, developed in the 19th century, was elaborated to test torsional resistance of manual stainless-steel (SS) files, but in clinical practice nickel-titanium rotary files rotate at higher values of speed compared to manual SS files [17]. Therefore, the ISO testing methodology is no longer coherent with the daily use of rotary files. Thus, the above-cited 3630-01 testing method should be changed in favour of a methodology more similar to the clinical application of nickel-titanium rotary instruments [18].

The AF Blue S4 (Fanta Dental Co. Ltd, Shangai, China) is a recently introduced sequence of heattreated instrument on the marketplace. The instruments present a convex triangular cross-section with three cutting blades along the cutting surface. For this study, the chosen instrument was the one that presents a tip diameter of 25 and $6 \%$ constant taper along the whole instrument [19].

The S-One (Fanta Dental CO., Ltd, Shangai, China) is a heat-treated instrument introduced by the manufacturer, thought to be used in a single file system technique in continuous rotation. The instrument presents a peculiar design: a tip diameter of $25,6 \%$ constant taper and an S-Shaped cross-section with variable mass center [20]. Both the instruments as mentioned above present a new heat-treated alloy the AF-R wire (Fanta Dental CO., Ltd, Shangai, China). The AF-R wire is a proprietary heat treatment not disclosed by the manufacturer, and the only published study demonstrates the influence of this wire on cyclic fatigue resistance $[20]$. 
According to manufacturer declaration, the two instruments have the same amount of total metal mass. Therefore, since metal mass and heat treatment are the same, the only difference is metal mass distribution. The present study aimed to evaluate the difference in torsional resistance between AF Blue S4 and S One with a new torsional resistance device, differing from the ISO standard just for the rotational speed.

\section{Material and Methods}

Study Design

A total of 40 new Nickel-Titanium instruments of $25 \mathrm{~mm}$ in length were tested in this in vitro study and randomly divided, using simple randomization technique, in two groups: Group A 20 AF Blue S4, tip size 25 and 6\% constant taper and Group B 20 AF-Blue S4, tip size 25 and 6\% constant taper (Figure 1). Before undergoing through the tests, all instruments were analyzed with x20 magnification (SMZ 745T; Nikon, Tokyo, Japan) by the same experienced operator and no manufacturing defects, such as microcracks, stretching/straightening of twist contour, cutting edge dented [21,22].

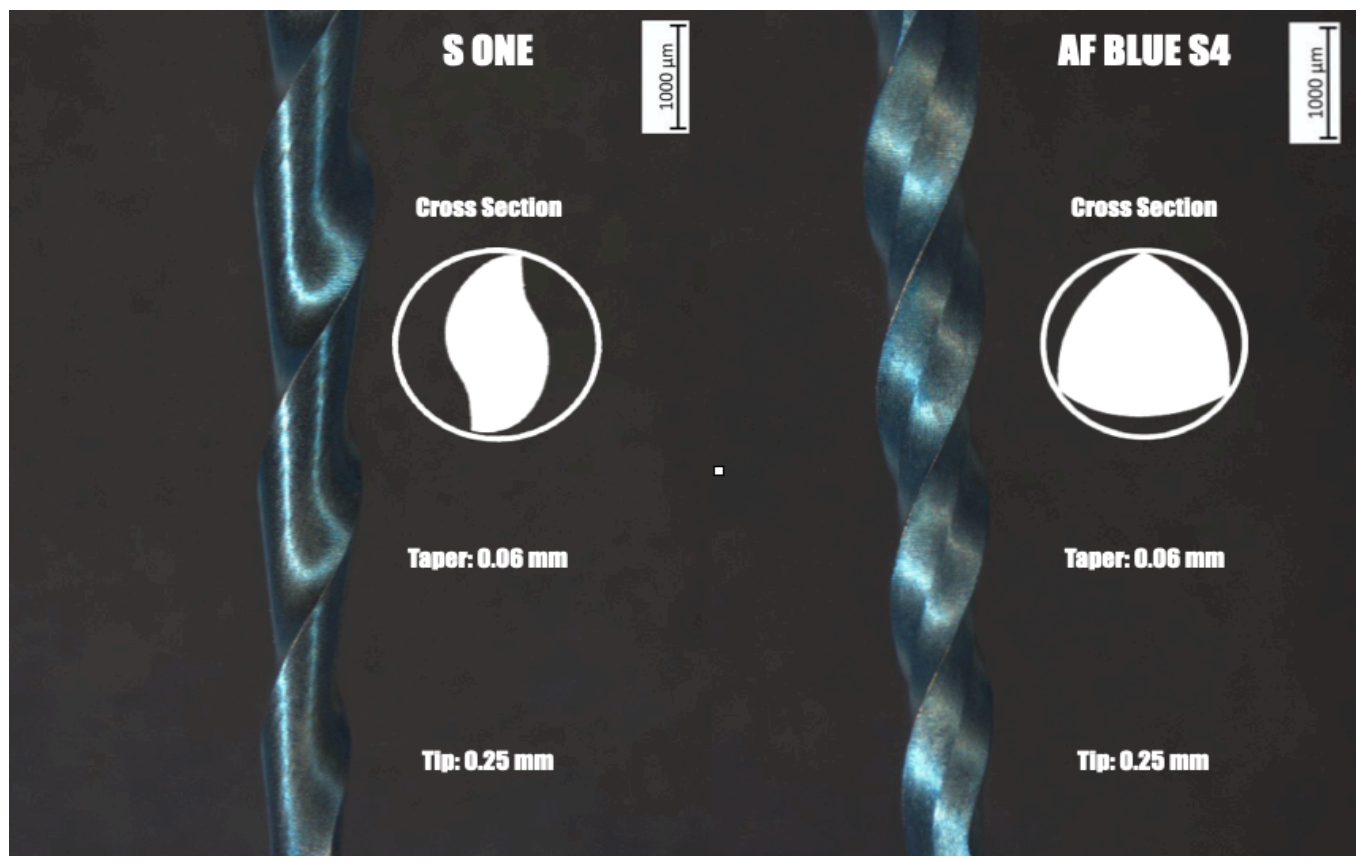

Figure 1. A schematic picture with a focus on macro-geometry of S-One and AF Blue S4.

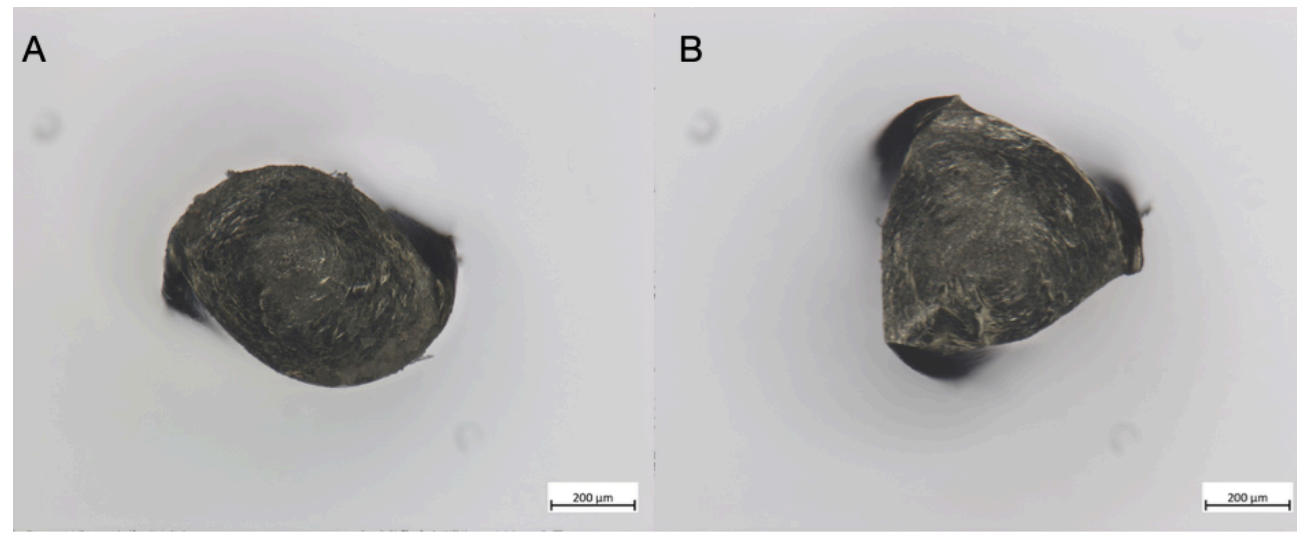

Figure 2. Cross-sectional design of S-One (A) and AF Blue S4 (B). 
The torsional test was performed using a torque recording endodontic motor (KaVo, Biberac, Germany). This endodontic motor could register in terms of 1/10 second the variation of generating torque of the instrument. This device was already validated in a previously published study [18]. To ensure an immovable block at $3 \mathrm{~mm}$ of the instrument tip, an auto-polymerizing resin (DuraLay; Reliance Dental Mfg Co, Worth, IL) was used using a plastic envelope as mold. The structure was then stuck with a vise.

Each file was rotated clockwise at a speed of $300 \mathrm{rpm}$ until fracture occurred. The torque limit was set at $5.5 \mathrm{Ncm}$. Angular deflection (AD) and Torque to Fracture (TtF) were recorded. Fragments lengths (FL) of the instrument's tip were measured using a digital caliper. The data were collected, mean and standard deviation were calculated.

\section{Data Analysis}

Data were statistically analyzed using the SPSS 17.0 software (IBM SPSS Inc., Chicago, IL, USA). Differences among groups were statistically evaluated with t-student test and the significance level was set at $P<0.05$

\section{Results}

Group A (AF Blue S4) showed higher TtF and AD than Group B (S-One). As illustrated in Table 1, $\mathrm{TtF}$ and $\mathrm{AD}$ for each instrument were recorded and statistical analysis found significant differences between the two groups $(\mathrm{p}<0.05)$. Group A (AF Blue S4) showed higher TtF and AD than Group B (S-One). Mean values for fragment length showed no significant differences $(\mathrm{p}<0.05)$ between the two instruments.

Table 1. Mean values for torque to fracture and Fragment Length.

\begin{tabular}{ccccc}
\hline & Group & $\begin{array}{c}\text { Torque to Fracture (TtF) } \\
\text { Mean (SD) }\end{array}$ & $\begin{array}{c}\text { Angular Deflection (AD) } \\
\text { Mean (SD) }\end{array}$ & $\begin{array}{c}\text { Fragment Length (FL) } \\
\text { Mean (SD) }\end{array}$ \\
\hline $\mathrm{A}$ & $1.277 \pm 0.262 \mathrm{Ncm}$ & $510 \pm 35.5^{\circ}$ & $2.941 \pm 0.300 \mathrm{~mm}$ \\
$\mathrm{~B}$ & $1.702 \pm 0.146 \mathrm{Ncm}$ & $660 \pm 46^{\circ}$ & $3.041 \pm 0.367 \mathrm{~mm}$ \\
& p-value & 0.0012 & - & 0.617 \\
\hline
\end{tabular}

\section{Discussion}

Fracture of NiTi rotary instruments during usage remains a serious concern because it occurs with permanent microscopic deformation and thus without visual warnings [23]. Therefore, in endodontic research, increasing fracture resistance is an important issue. To date, many previously published studies investigated fracture resistance of NiTi rotary instruments. This is determined by material properties, i.e., modulus of elasticity and rigidity, environmental working conditions, such as temperature, mass and geometric design [24-27]. Furthermore, clinical motion can influence the torsional resistance [28,29]. On the other hand, it is well known that some other characteristics, such as different irrigation methods, does not influence torsional resistance [30,31]. To clearly investigate the influence of each of these parameters on mechanical behavior of NiTi files, each of them should be investigated separately. Nevertheless, the major problem in carrying out this type of research is that it is often difficult to standardize each of the above factors. The comparison between two files with the same design, dimensions, and heat treatment could be influenced by slightly different raw material and grinding machines. In order to avoid such problems, the two files used in the present study have no differences in grinding machining and thermal treatment. Moreover, to avoid errors due to different raw material, the files were obtained from the same lot of nickel-titanium [32]. 
The AF Blue S4 and S-One present the same tip dimension, 25, and taper, 6\%. In addition, the two instruments share the same amount of metal mass, according to manufacturer declaration.

According to the result of the present study, the AF Blue S4 exhibited higher torsional resistance and angular deflection than the S-One. There are no statistically relevant differences in fragment length. This demonstrates the validation of the testing device, ensuring a reproducible position of the NiTi rotary files $[10]$.

The only difference between the two instruments is the cross-sectional design. AF Blue S4 presents a convex triangular cross-section with three cutting blades along the cutting surface while the S-One has an Sshaped cross-section [33,34]. These two cross designs have a relevant difference in metal mass distribution, also known as polar moment of inertia, which is indeed the main parameter influencing the torsional resistance [35]. The polar moment of inertia is the mass distribution in relation to the rotation axis. The more mass is far from the rotation axis, the higher the moment of inertia will be. Indeed, in convex triangular design, a superior amount of mass is distributed far from the center of the instrument when compared with an s-shaped crosssection [36].

Torsional resistance is a mechanical property of the instrument that implies the file's ability to twist before fracture. This type of stress occurs in very tight canals where the file is subjected to high torsional load [37]. The metal mass of an instrument was investigated in literature both for cyclic fatigue resistance and torsional resistance $[2,7,37,38]$. Usually, greater the mass quantity of the instrument, greater the polar moment of inertia will be [37]. Nevertheless, previously published articles demonstrated as this statement is not always true. Peculiar instrument design with the same amount of mass along the whole instrument but a different polar moment of inertia could exist. The result of the present study confirms the influence of mass distribution over total mass amount in torsional resistance [39].

Evaluating the mechanical properties and motion of the NiTi files is essential for clinicians to select the system that improves clinical outcomes [40]. Once the torsional strength of the file is exceeded, intracanal file fracture can occur. Despite that, the torsional resistance of the two files, both subjected to the same AF-R wire proprietary thermal treatment, is similar to the resistance of other files such as F2 of Protaper Gold, from already published in literature [25]. These findings demonstrate the effectiveness and safety of these new files, thanks to their similarity with the root canal shaping milestone.

\section{Conclusion}

Although the present methodology does not mimic exactly the clinical setting, according to the result of this study, AF Blue $\mathrm{S} 4$ has higher torque at fracture when compared to S-One. Indeed, the use of AF Blue $\mathrm{S} 4$ seems safer regarding resistance to torsional stress in vitro. Anyway, further in vitro and in vivo studies are needed to better understand the clinical role of torsional stresses.

\section{Authors' Contributions}

\begin{tabular}{|c|c|c|}
\hline GG & (iD) $0000-0002-9815-5689$ & Conceptualization. \\
\hline GM & (iD) $0000-0002-0068-0080$ & Methodology. \\
\hline $\mathrm{DDN}$ & (iD) $0000-0002-5054-0828$ & Supervision. \\
\hline $\mathrm{ADG}$ & (iD) $0000-0002-8191-663 \mathrm{X}$ & Investigation and Formal Analysis. \\
\hline $\mathrm{AM}$ & (iD) $0000-0002-5050-5993$ & Investigation and Formal Analysis. \\
\hline MS & (iD) $0000-0001-6104-921 \mathrm{X}$ & Writing - Review and Editing. \\
\hline LT & (iD) $0000-0003-3904-3000$ & Writing - Original Draft Preparation. \\
\hline
\end{tabular}




\section{Financial Support}

None.

\section{Conflict of Interest}

The authors declare no conflicts of interest.

\section{References}

[1] Mehlawat R, Kapoor R, Gandhi K, Kumar D, Malhotra R, Ahuja S. Comparative evaluation of instrumentation timing and cleaning efficacy in extracted primary molars using manual and NiTi rotary technique - in vitro study. J Oral Biol Craniofac Res 2019; 9(2):151-5. https://doi.org/10.1016/j.jobcr.2019.03.003

[2] Di Nardo D, Galli M, Morese A, Seracchiani M, Ferri V, Miccoli G, et al. A comparative study of mechanical resistance of two reciprocating files. J Clin Exp Dent 2019; 11(3):e231-e235. https://doi.org/10.4317/jced.55487

[3] Pedullà E, La Rosa GRM, Virgillito C, Rapisarda E, Kim HC, Generali L. Cyclic fatigue resistance of nickel-titanium rotary instruments according to the angle of file access and radius of root canal. J Endod 2020; 46(3):431-6. https://doi.org/10.1016/j.joen.2019.11.015

[4] Generali L, Puddu P, Borghi A, Brancolini S, Lusvarghi L, Bolelli G, et al. Mechanical properties and metallurgical features of new and ex vivo used Reciproc Blue and Reciproc. Int Endod J 2020; 53(2):250-64. https://doi.org/10.1111/iej.13214

[5] Sattapan B, Palamara JE, Messer HH. Torque during canal instrumentation using rotary nickel-titanium files. J Endod 2000; 26(3):156-60. https://doi.org/10.1097/00004770-200003000-00007

[6] Gambarini G, Miccoli G, Seracchiani M, Morese A, Piasecki L, Gaimari G, et al. Fatigue resistance of new and used nickel-titanium rotary instruments: a comparative study. Clin Ter 2018; 169(3):e96-e101. https://doi.org/10.7417/t.2018.2061

[7] Elnaghy AM, Elsaka SE, Elshazli AH. Dynamic cyclic and torsional fatigue resistance of TruNatomy compared with different nickel-titanium rotary instruments. Aust Endod J 2020. https://doi.org/10.1111/aej.12396

[8] Uygun AD, Unal M, Falakaloglu S, Guven Y. Comparison of the cyclic fatigue resistance of Hyflex EDM, Vortex blue, Protaper gold, and Onecurve nickel-Titanium instruments. Niger J Clin Pract 2020; 23(1):41-5.

[9] Gambarini G, Galli M, Di Nardo D, Seracchiani M, Donfrancesco O, Testarelli L. Differences in cyclic fatigue lifespan between two different heat treated NiTi endodontic rotary instruments: WaveOne Gold vs EdgeOne Fire. J Clin Exp Dent 2019; 11(7):e609-e613. https://doi.org/10.4317/jced.55839

[10] Miccoli G, Gaimari G, Seracchiani M, Morese A, Khrenova T, Di Nardo D. In vitro resistance to fracture of two nickel-titanium rotary instruments made with different thermal treatments. Ann Stomatol 2017; 8(2):53-8.

[11] Oh SH, Ha JH, Kwak SW, Ahn SW, Lee W, Kim HC. The effects of torsional preloading on the torsional resistance of nickel-titanium instruments. J Endod 2017; 43(1):157-62. https://doi.org/10.1016/j.joen.2016.10.005

[12] Di Nardo D, Seracchiani, M, Mazzoni A, Del Giudice A, Gambarini G, Testarelli L. Torque range, a new parameter to evaluate new and used instrument safety. Appl. Sci 2020; 10(10):3418. https://doi.org/10.3390/app10103418

[13] Oh S, Kum KY, Cho K, Lee SH, You SH, Go J, et al. Torsional and bending properties of V Taper 2H, ProTaper NEXT, NRT, and One Shape. Biomed Res Int 2019; 2019:6368958. https://doi.org/10.1155/2019/6368958

[14] Busquim SSK, Santos M. Cervical shaping in curved root canals: comparison of the efficiency of two endodontic instruments. Pesqui Odontol Bras 2002; 16(4):327-31. https://doi.org/10.1590/s1517-74912002000400008

[15] Inan U, Keskin C. Torsional resistance of ProGlider, Hyflex EDM, and OneG Glide Path instruments. J Endod 2019; 45(10):1253-7. https://doi.org/10.1016/j.joen.2019.06.012

[16] International Organization for Standardization. ISO 3630-1:2008 Dentistry Root-Canal Instruments - Part 1: General Requirements and Test Methods. Available from: https://www.iso.org/standard/37702.html. [Accessed on March 05, 2020].

[17] Bartols A, Bormann C, Werner L, Schienle M, Walther W, Dörfer CE. A retrospective assessment of different endodontic treatment protocols. PeerJ 2020; 8:e8495. https://doi.org/10.7717/peerj.8495

[18] Fanta Dental Materials Co. Internal Studies. Available from: https://www.fantausa.com/resources. [Accessed on March 05, 2020].

[19] Ozlek E, Neelakantan P, Khan K, Cheung GSP, Rossi-Fedele G. Debris extrusion during root canal preparation with nickel-titanium instruments using liquid and gel formulations of sodium hypochlorite in vitro. Aust Endod J 2020. https://doi.org/10.1111/aej.12424

[20] Keskin C, Inan U, Demiral M, Keleş A. Cyclic fatigue resistance of Reciproc Blue, Reciproc, and WaveOne Gold reciprocating instruments. J Endod 2017; 43(8):1360-3. https://doi.org/10.1016/j.joen.2017.03.036

[21] Gambarini G, Seracchiani M, Piasecki L, Obino FV, Galli M, Di Nardo D, et al. Measurement of torque generated during intracanal instrumentation in vivo. Int Endod J 2019; 52(5):737-45. https://doi.org/10.1111/iej.13042 
[22] Chakka NVMK, Ratnakar P, Das S, Bagchi A, Sudhir S, Anumula L. Do NiTi instruments show defects before separation? Defects caused by torsional fatigue in hand and rotary nickel-titanium (NiTi) instruments which lead to failure during clinical use. J Contemp Dent Pract 2012; 13(6):867-72. https://doi.org/10.5005/jp-journals-100241243

[23] Ha JH, Kwak SW, Kim SK, Sigurdsson A, Kim HC. Effect from rotational speed on torsional resistance of the nickeltitanium instruments. J Endod 2017; 43(3):443-6. https://doi.org/10.1016/j.joen.2016.10.032

[24] Di Nardo D, Miccoli G, Mazzoni A, Seracchiani M, Gambarini G, Testarelli L. Centering ability of a new nickeltitanium rotary instruments with a peculiar flat-side design: an in vitro study. J Contemp Dent Pract 2020; 21(5):53942. https://doi.org/10.5005/jp-journals-10024-2829

[25] Almeida GC, Guimarães LC, Resende PD, Buono VTL, Peixoto IFC, Viana ACD. Torsional behaviour of Reciproc and Reciproc blue instruments associated with their martensitic transformation temperatures. Int Endod J 2019; 52(12):1768-72. https://doi.org/10.1111/iej.13185

[26] Alqedairi A, Alfawaz H, Abualjadayel B, Alanazi M, Alkhalifah A, Jamleh A. Torsional resistance of three ProTaper rotary systems. BMC Oral Health 2019;19(1):124. https://doi.org/10.1186/s12903-019-0820-7

[27] Dioguardi M, Sovereto D, Aiuto R, Laino L, Illuzzi G, Laneve E, et al. Effects of hot sterilization on torsional properties of endodontic instruments: Systematic review with meta-analysis. Materials 2019; 12(13):2190. https://doi.org/10.3390/ma12132190

[28] Karataş E, Arslan H, Büker M, Seçkin F, Çapar ID. Effect of movement kinematics on the cyclic fatigue resistance of nickel titanium instruments. Int Endod J 2016; 49(4):361-4. https://doi.org/10.1111/iej.12453

[29] Kim HC, Kwak SW, Cheung GSP, Ko DH, Chung SM, Lee W. Cyclic fatigue and torsional resistance of two new nickel-titanium instruments used in reciprocation motion: Reciproc versus WaveOne. J Endod 2012; 38(4):541-4. https://doi.org/10.1016/j.joen.2011.11.014

[30] Barbosa FOG, Gomes JACP, Araújo MCP. Influence of sodium hypochlorite on mechanical properties of K3 nickeltitanium rotary instruments. J Endod 2007; 33(8):982-5. https://doi.org/10.1016/j.joen.2007.05.008

[31] Peters OA, Roehlike JO, Baumann MA. Effect of immersion in sodium hypochlorite on torque and fatigue resistance of nickel-titanium instruments. J Endod 2007; 33(5):589-93. https://doi.org/10.1016/j.joen.2007.01.007

[32] Gambarini G, Miccoli G, Seracchiani M, Khrenova T, Donfrancesco O, D’Angelo M, et al. Role of the flat-designed surface in improving the cyclic fatigue resistance of endodontic NiTi rotary instruments. Materials 2019; 12(16):2523. https://doi.org/10.3390/ma12162523

[33] Kwak SW, Lee JY, Goo HJ, Kim HC. Effect of surface treatment on the mechanical properties of nickel-titanium files with a similar cross-section. Restor Dent Endod 2017; 42(3):2 16-23. https://doi.org/10.5395/rde.2017.42.3.216

[34] Park SY, Cheung GSP, Yum J, Hur B, Park JK, Kim HC. Dynamic torsional resistance of nickel-titanium rotary instruments. J Endod 2010; 36(7):1200-4. https://doi.org/10.1016/j.joen.2010.02.016

[35] Versluis A, Kim HC, Lee W, Kim BM, Lee CJ. Flexural stiffness and stresses in nickel-titanium rotary files for various pitch and cross-sectional geometries. J Endod 2012; 38(10):1399-403. https://doi.org/10.1016/j.joen.2012.06.008

[36] Yum J, Cheung GSP, Park JK, Hur B, Kim HC. Torsional strength and toughness of nickel-titanium rotary files. J Endod 2011; 37(3):382-6. https://doi.org/10.1016/j.joen.2010.11.028

[37] Gambarini G, Galli M, Seracchiani M, Di Nardo D, Versiani MA, Piasecki L, et al. In vivo evaluation of operative torque generated by two nickel-titanium rotary instruments during root canal preparation. Eur J Dent 2019; 13(4):556-62. https://doi.org/10.1055/s-0039-1698369

[38] Pedullà E, Lo Savio F, La Rosa GRM, Miccoli G, Bruno E, Rapisarda S, et al. Cyclic fatigue resistance, torsional resistance, and metallurgical characteristics of M3 Rotary and M3 Pro Gold NiTi files. Restor Dent Endod 2018; 43(2):e25. https://doi.org/10.5395/rde.2018.43.e25

[39] Grande NM, Plotino G, Butti A, Messina F, Pameijer CH, Somma F. Cross-sectional analysis of root canals prepared with NiTi rotary instruments and stainless steel reciprocating files. Oral Surg Oral Med Oral Pathol Oral Radiol Endod 2007; 103(1):120-6. https://doi.org/10.1016/j.tripleo.2005.12.022

[40] Gambarini G, Di Nardo D, Miccoli G, Guerra F, Di Giorgio R, Di Giorgio G, et al. The influence of a new clinical motion for endodontic instruments on the incidence of postoperative pain. Clin Ter 2017; 168(1):e23-e27. https://doi.org/10.7417/ct.2017.1977 